Florida International University

FIU Digital Commons

FIU Electronic Theses and Dissertations

University Graduate School

3-30-2004

\title{
The effects of varied retrieval cues on reminiscence in eyewitness memory
}

Julian A.E. Gilbert

Florida International University

Follow this and additional works at: https://digitalcommons.fiu.edu/etd

Part of the Psychology Commons

\section{Recommended Citation}

Gilbert, Julian A.E., "The effects of varied retrieval cues on reminiscence in eyewitness memory" (2004). FIU Electronic Theses and Dissertations. 3936.

https://digitalcommons.fiu.edu/etd/3936

This work is brought to you for free and open access by the University Graduate School at FIU Digital Commons. It has been accepted for inclusion in FIU Electronic Theses and Dissertations by an authorized administrator of FIU Digital Commons. For more information, please contact dcc@fiu.edu. 
FLORIDA INTERNATIONAL UNIVERSITY

Miami, Florida

THE EFFECTS OF VARIED RETRIEVAL CUES

ON REMINISCENCE IN EYEWITNESS MEMORY

A thesis submitted in partial fulfillment of the

requirements for the degree of

MASTER OF SCIENCE

in

PSYCHOLOGY

by

Julian A.E. Gilbert

2004 
To: Dean R. Bruce Dunlap

College of Arts and Sciences

This thesis, written by Julian A.E. Gilbert, and entitled The Effects of Varied Retrieval Cues on Reminiscence in Eyewitness Memory, having been approved in respect to style and intellectual content, is referred to you for judgment.

We have read this thesis and recommend that it be approved.

Janat Parker

Christian Meissner

Ronald P. Fisher, Major Professor

Date of Defense: March 30, 2004

The thesis of Julian A.E. Gilbert is approved.

Dean R. Bruce Dunlap College of Arts and Sciences

Dean Douglas Wartzok University Graduate School

Florida International University, 2004 


\section{ACKNOWLEDGMENTS}

I first wish to thank Mohammed Ziadeh, Toji Berlin, and Claudia Oliva for their invaluable assistance in coding and scoring the data presented in this thesis. I realize it was a tedious process but without their dedication and hard work, the completion of this project would not have been possible.

I also wish to thank the members of my thesis committee for their patience, guidance and assistance throughout this entire process. Dr. Janat Parker was particularly helpful towards the final stages of the project. Her eye for detail and excellent recommendations were invaluable in finishing the thesis. Dr. Christian Meissner was especially helpful in planning and executing the analysis for this project. He was also a constant source of encouragement. Finally, I wish to thank my major professor, Dr. Ronald Fisher, whose previous work served as the impetus for this project. He played an essential role at each and every step of this project and was always willing to offer crucial assistance and guidance on the many drafts of the thesis. He was a role model for precision and quality in research and his uncompromising pursuit of excellence serves as an inspiration to me. 


\section{ABSTRACT OF THE THESIS \\ THE EFFECTS OF VARIED RETRIEVAL CUES \\ ON REMINISCENCE IN EYEWITNESS MEMORY}

by

Julian A.E. Gilbert

Florida International University, 2004

Miami, Florida

Professor Ronald P. Fisher, Major Professor

It is not uncommon for eyewitnesses to recall things at later interviews that were not recalled at previous interviews (reminiscence). Many legal decision makers assume that inconsistent eyewitnesses are necessarily inaccurate witnesses. Consequently, their testimony may be prematurely discredited or dismissed. In order to examine the effectiveness of various retrieval cues in eliciting reminiscence, participants watched a videotaped mock crime and were tested for recall on two occasions using the same or different cues. Results supported the hypothesis that varying retrieval cues increases the amount of reminiscence. Furthermore, all participants exhibited some reminiscence. Finally, reminiscence was not significantly correlated with overall accuracy of testimony. These findings suggest that many of the assumptions legal decision makers hold regarding inconsistent testimony are erroneous. 


\section{TABLE OF CONTENTS}

CHAPTER

PAGE

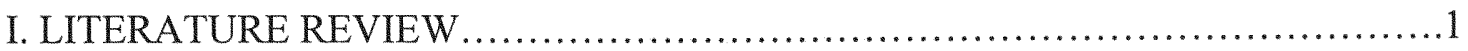

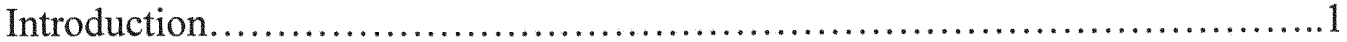

Types of Inconsistencies.................................................... 3

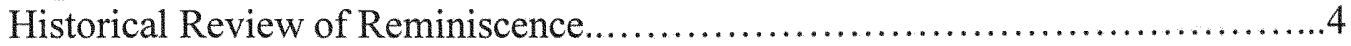

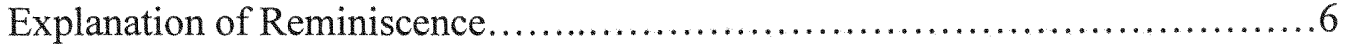

Theoretical Rationale...................................................... 7

Factors Affecting Reminiscence......................................... 9

Characteristics of an Event and Selection of Retrieval Cues.....................13

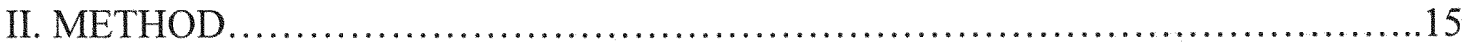

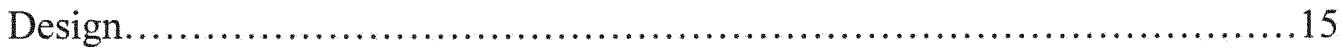

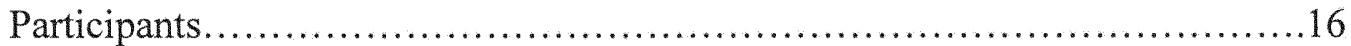

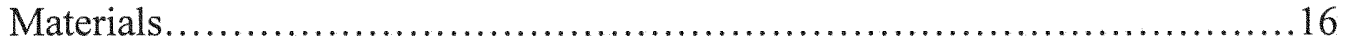

Procedure............................................................. 17

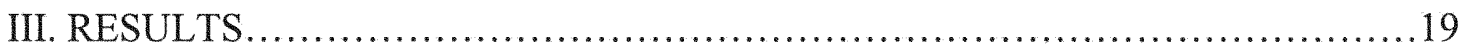

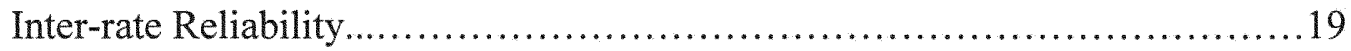

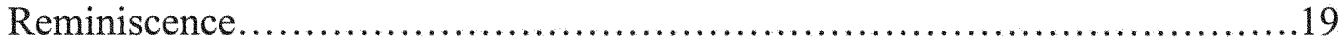

Forgotten, Consistent, and Contradictory Details...........................20

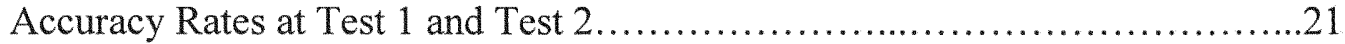

Accuracy Rates for Types of Details.....................................21

Relation between Reminiscent Details and Overall Accuracy...................23

Correlations of Forgotten, Consistent, and Contradictory Details with Overall Accuracy Rate.................................................23

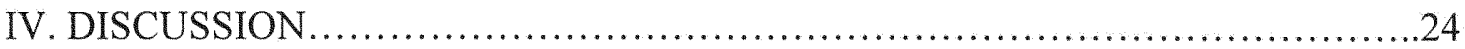

Varying Retrieval Cues and Reminiscence...................................25

Forgetting, Reminiscence and Output Interference...........................26

Changing Cues Increases Reminiscence and Decreases Forgetting ..............27

Accuracy of Individual Statements............................................28

Accuracy of Witness ...................................................... 30

Potential Limitations ....................................................... 31

Caveat for Multiple Testing .....................................................34

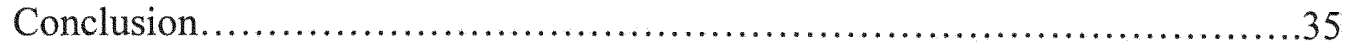

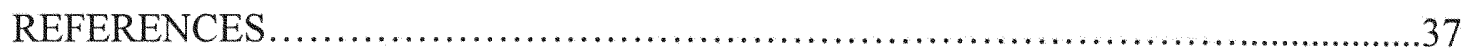




\section{Chapter One: Literature Review}

Introduction

The resolution of a crime is often contingent on the completeness and accuracy of eyewitness accounts. A survey of law enforcement agents in New York reflected this belief, with most claiming that eyewitnesses are the central and most important feature in a criminal investigation (cited in Fisher, Geiselman, \& Amador, 1989). Moreover, eyewitness testimony is often the primary source of evidence provided in a trial, and consequently, can profoundly influence jurors' beliefs and judgments (cited in Fisher, Mello, \& McCauley, 1999). Perhaps more important than the actual evidence provided by an eyewitness is the juror's perceived credibility of that witness. Several factors are known to affect the perceived credibility of a witness (e.g., self-confidence) but one in particular may unduly influence juries-inconsistencies in an eyewitness account.

Eyewitnesses are often interviewed repeatedly in a typical criminal investigation. For instance, a uniformed officer may take an initial report, a detective may question a witness at a later date as part of the investigation, and attorneys representing both the prosecution and the defense will likely be interested in an eyewitness account. Yet the legal system has always been wary about the repeated interviewing of witnesses, often claiming that such repetition prompts confabulations (Dunning \& Stern, 1992). For instance, according to one system of assessing the accuracy of eyewitness reports, the Statement Validity Assessment System (VAS), one indicator of an assertion's accuracy is whether the witness said it in an early or late interview. Statements that appear only in later interviews are considered likely confabulations or distortions (Dunning \& Stern, 1992). An opposing attorney, for example, will likely use such inconsistent testimony to 
discredit a witness, asserting that the details recalled only in a later interview must have been planted - why else would these details not be recalled in initial interviews?

However, this reflexive belief among legal decision makers is not supported by the psychological research. In fact, past research supports the notion that such reminiscent inconsistencies are a natural product of repeated testing (see Dent \& Stephenson, 1979; Scrivner \& Safer, 1988; Dunning \& Stern, 1992; Turtle \& Yuille, 1994).

Given the variety of conditions under which various interviews are conducted and the different motives of the interviewers, it should not be surprising that inconsistencies often arise in eyewitness accounts. Nonetheless, attorneys, judges and jurors hold the imprudent belief that inconsistent witnesses will also be inaccurate and unreliable. An informal survey of judges and lawyers revealed that they strongly believe inconsistency to reflect inaccurate testimony (Fisher \& Cutler, 1995). Consequently, it is a well-advised practice for attorneys to try to elicit inconsistencies when cross-examining a witness. In fact, the opposing attorney's main strategy in cross-examination is to discredit the witness (Mueller \& Kirkpatrick, 1996). As noted defense lawyer F. Lee Bailey has clearly stated, "Capitalize on...conflicts [in a witness's testimony]. This is the most effective way of discrediting [the witness's] entire testimony" (quoted in Fisher \& Cutler, 1995). Despite this popular view among legal decision makers, the results of several studies reveal only a weak relationship between inconsistency and inaccuracy of testimony (Fisher \& Cutler, 1995; Brewer, Potter, Fisher, Bond, \& Luszcz, 1999). Moreover, the accuracy of statements related to one dimension of testimony is not correlated with the accuracy in relation to another, suggesting that a witness's entire testimony should not be disregarded due to known inaccuracies in one area of their 
statements. Inconsistencies apparently occur for reasons specific to a particular area of testimony and not due to some characteristic of the overall memory for the event (Brewer et al., 1999).

\section{Types of inconsistencies}

There are basically three kinds of inconsistencies that can arise in an eyewitness's account, and a lawyer, judge or juror may view any one of them as reason to discredit or, worse yet, impeach a witness. Perhaps the most detrimental to a witness's perceived credibility, contradictions arise when specific details recalled at one interview differ at another interview time (e.g., a witness claimed the assailant had a beard at one interview but later claimed he was clean-shaven). Fortunately, contradictions are not all that common in eyewitness accounts. The second type of inconsistency involves forgotten details. This inconsistency arises when details recalled at an earlier interview are not recalled in a later interview. Most people share the belief that such discrepancies are a natural occurrence, as things tend to be forgotten with the passage of time. The third kind of inconsistency involves reminiscent details, which can be viewed as the opposite of forgotten details. Reminiscence occurs when details are recalled at later interviews that were not recalled at previous ones. As previously noted, the results of past research have demonstrated that reminiscence is a very common, reliable, and natural phenomenon. Nonetheless, reminiscent details may be used to discredit or even impeach a witness.

A hostile attorney will likely attack reminiscent details, claiming, for example, that the previously unrecalled details were planted during a more recent interview, or that the eyewitness conjured up these "new" details. Numerous books on cross-examination stress the importance of eliciting inconsistencies from a hostile witness (see Dombroff, 
1985; Ponzer \& Dodd, 1993; Iannuzzi, 1999). For instance, Glissan (1991) emphasizes capitalizing on, or even "manufacturing", such inconsistencies in testimony to "destroy a witness, and sometimes a whole case" (p. 108). Jurors will likely interpret inconsistencies in testimony as a sign of inaccurate testimony. Indeed, a recent study found that potential jurors considered inconsistent statements to be very indicative of testimonial inaccuracy (Brewer et al., 1999). Jurors may be unduly influenced by the presence of reminiscent details and assume that such inconsistent testimony reflects inaccuracy. With the credibility of the witness tainted, the rest of his or her testimony may be questioned or ignored. Valuable testimony can thus be lost due to the erroneous views of legal decision makers regarding reminiscence.

Historical review of reminiscence

The phenomenon of reminiscence has been largely ignored in psychological research, although the concept was first examined nearly a century ago. Ballard initially coined the term reminiscence in 1913 to refer to 'the remembering again of the forgotten without re-learning' (quoted in Payne, 1987). Ballard witnessed this counter-intuitive phenomenon after many of his students increased their recall performance across repeated tests using lines of poetry as his stimulus material. Considering that Ballard's findings flew in the face of the pervasive view put forth by Ebbinghaus' classic forgetting function, reminiscence received a fair amount of attention in the 1920s and 1930s. In 1923, Brown demonstrated that a large proportion (almost 20\%) of items not initially recalled appeared in a later test without any additional study time. Nicolai (1921) obtained significant amounts of reminiscence for both adults and children with multiple 
recall tests extending over months, demonstrating the longevity of the phenomenon (Erdelyi, 1996).

Despite some early successful replications of the reminiscence phenomenon, subsequent researchers working in the 1930s and 1940s failed to obtain reminiscence. Covert review and participant's practicing recalling the to-be remembered (TBR) items during the retention interval were cited as the main causes of the initial findings of Ballard, Brown, and other researchers. Many psychologists argued that reminiscence was the result of the additional retrieval or practice time that accompanied additional testing opportunities. Improvements on delayed tests were attributed to practice effects produced by giving participants immediate recall tests, with the earlier tests serving the same function as additional study opportunities. It was thus deemed that a true reminiscence effect could be obtained only after one ruled out any test-retest effects (Payne, 1987). However, more recent research has shown that review during retention intervals or practice effects arising from repeated testing are not factors in producing reminiscence (Payne, 1987; Erdelyi, 1996). Turtle and Yuille (1994) even allowed participants to review their previous statements but that review had no effect on the number of items recalled (although reminiscence certainly occurred). In addition to the failure to replicate previous findings and the belief in practice effects as a cause of reminiscence, definitional inconsistencies plagued the phenomenon, even from the beginning. Ballard, who originally defined the concept, also used the term reminiscence to refer to increases in net recall across successive tests (this definition of reminiscence as increase in net recall across tests was widely held until 1974 when Erdelyi and Becker used this definition for hypermnesia). As a result of the definitional problems and the failure to replicate original 
findings, reminiscence was commonly viewed as elusive and interest in the phenomenon waned from the 1940s to the 1970 s.

After Erdelyi and Becker (1974) defined hypermnesia as the improvements in net recall levels associated with increasing inter-test intervals, reminiscence was defined as either the recall of previously unrecalled TBR items or as the improvements in gross recall levels associated with successive tests. Since reminiscence is not masked by forgetting (as is hypermnesia), it might be considered a more sensitive indicator of recall improvement and the more ubiquitous of the phenomena. In fact, given the current definitions of reminiscence, every study examined in an extensive review has found some evidence of reminiscence; it is arguably on par with forgetting as a natural and common phenomenon (Erdelyi, 1996). Unfortunately, legal decision makers do not seem to be aware of how common and natural reminiscence effects are and how such "inconsistencies" should not necessarily be a viable reason to brand a witness as inaccurate and unreliable.

\section{Explanation of reminiscence}

Given that the phenomenon has been readily found in practically every study examining reminiscence, it should not be surprising that reminiscence is viewed on par with forgetting as a natural phenomenon (Erdelyi, 1996). Despite how common it is though, there are not many explanations available for reminiscence. One very feasible account utilizes the notion of varied retrieval. There may be several retrieval paths to a stored event, so that information not obtained using one retrieval cue may be accessible with the use of a different cue. Since each retrieval cue has some probability of accessing stored details of an event, providing various cues over test trials should increase the 
number of details recalled. Reminiscence arises when retrieval is varied between test trials and results from a person searching his or his memory differently on two occasions. New retrieval cues given in between test trials can elicit additional details not previously remembered (i.e., reminiscence) because they offer the participants/witnesses a novel way to search their memory. For example, say a police officer is questioning a witness at a crime scene. That witness searches his or her memory in a specific manner (e.g., based on the officer's questions such as the perpetrator's race, height, vehicle, or weapon), until that "pool" of information in the witness" head is believed to be exhausted (i.e., the witness cannot recall any more details based on the questions). But if the witness thinks about the event again in a different manner (e.g., recreating the original emotional and physical context or thinking about the event in reverse order) he or she may utilize a different retrieval path to the crime and new details may be recalled. In other words, varied retrieval allows the witness novel ways of searching through memory, which increases the likelihood that previously unrecalled details will be recollected. The result is the phenomenon of reminiscence if the cues are varied between test trials or interviews. Theoretical rationale

There are several previous lines of research that give credence to the notion that varied retrieval may account for reminiscence. First, according to Tulving and Watkins (1975), there are three classes of observable entities always involved in remembering: the input into the memory system, the retrieval cue(s) behind the process of retrieval, and the actual output from the system (i.e., what is recalled). Recollection (the output) is a product of both the stored input and the retrieval cue(s) used for recollection. Changing the retrieval cue used in a recollection attempt alters the process of retrieval, and 
consequently, what information is remembered. Forgetting (failure of retrieval of an event in a test following the successive retrieval of the same event in an earlier test) can be viewed as a cue-dependent phenomenon, reflecting the idea that the failed retrieval is due to an absence of the relevant retrieval cue(s). It follows logically then that appropriate variations in retrieval cues over consecutive tests should produce the reversal of forgetting (i.e., reminiscence) (Tulving, 1974).

Second, the revised Cognitive Interview (CI), developed by Fisher and Geiselman (1992), is a technique that has been found to increase the number of correct details that witnesses recall in an interview without a significant increase in errors (Chandler \& Fisher, 1996). The CI is important to the current discussion because the CI implemented and applied the idea that varied retrieval can bolster the amount of information gained by a witness. There are two components of the $\mathrm{CI}$ relevant to the current discussion on varied retrieval and reminiscence: recalling an event in a multitude of orders and changing perspectives when recalling the event. The mnemonic of recalling an event in a variety of orders has previously been shown to effectively bolster the amount of information recalled (Whitten \& Leonard, 1981; Geiselman, Fisher, McKinnon, and Holland, 1986; Geiselman \& Callot, 1990). Varying how a witness recounts a crime can thus facilitate recall. For instance, a witness is instructed to recall a crime in forward order (retrieval cue "A") at an initial interview. Later, retrieval is varied by asking the witness to recount the crime in reverse order (retrieval cue "B"). Previously unrecalled TBR details will likely arise, resulting in the phenomenon of reminiscence.

The second mnemonic used by the CI that focuses on varied retrieval is that of changing perspectives. The Cl's reliance on the principle of changing perspectives was 
based primarily on the results of a study done by Anderson and Pichert (1978). Their research highlighted the point that altering retrieval cues (in this instance, perspective) can increase the number of details recalled. After reading a story about two boys playing hooky from school from either the perspective of a homebuyer or a burglar, participants were instructed to recall the story from one perspective (i.e., retrieval cue "A") before switching viewpoints (i.e., retrieval cue "B") and recalling the story again. They found that participants produced on the second recall significantly more information important to the second perspective that had been unimportant to the first perspective. The participants also recalled less information unimportant to the second perspective that had been important to the first. The researchers explained their results in terms of schema theory.

Schemata are abstract knowledge structures whose elements are other schemata, and slots, placeholders, or variables that take on a restricted range of values. Schemata are structured in the sense that they indicate typical relationships between component elements (Anderson \& Pichert, 1978). Each schema contains a restricted amount of information or knowledge contained within it. Therefore when a specific schema is used to recall the details of an event, the "pool" of information that the person draws from is limited to that specific dominant schema. In other words, utilizing a certain schema for recall results in information specific to that schema being produced. Changing dominant schemata via retrieval cues (e.g., using a "homebuyer" perspective at one time and a "burglar" perspective later) alters which "pool" of information a person uses in his or her recall attempt, which can result in new details being recalled (as shown in Anderson \& Prichert, 1978). 
Reminiscence is the result of varying retrieval strategies between test trials (e.g., by altering schemata via novel retrieval cues given before the trials). Information important or connected to the newly utilized schema will be elicited at the test trial that was unimportant or irrelevant to the schema previously used at an earlier test trial. According to the retrieval plan hypothesis, the new schema/cue may provide the witness implicit cues for different categories of information (Anderson \& Pichert, 1978). That is, if each schema provides a specific retrieval strategy, changing schemata between test trial one and two will alter the cues used by a person for recall. Reminiscence results from information connected to the new schema (but not connected to the previous schema) being recollected at trial two.

\section{Factors affecting reminiscence}

Although reminiscence is now viewed among most psychologists as a bedrock phenomenon, there are several factors that can affect the amount of reminiscence obtained including the type of stimulus material, the length of the recall periods, and the type of recall procedures. While the early findings of reminiscence were attributed, in large part, to the pictorial or image quality of the stimuli, it is now generally accepted that reminiscence will be obtained regardless of the type of stimulus material (Payne, 1987). However, Scrivner and Safer (1988) argue that reminiscence for details in a meaningful event (e.g., a crime) should be greater than reminiscence found with unrelated pictorial or verbal stimuli. Given that the details of the actions in an event are related and connect in some logical manner like a story, recalling one new detail at a later testing opportunity may jar a person's memory for other related but previously unrecalled details. For instance, an officer who uses direct, closed-ended questions to interview a witness to a 
crime may ask if the witness saw any getaway vehicle. The witness cannot recall seeing any vehicle. The witness is then interviewed again at a later date, this time by an attorney who instructs the witness to adopt the perspective of the perpetrator before going through the event. The witness suddenly remembers that the perpetrator did mention something about a getaway vehicle running outside. This new detail serves as an additional retrieval cue and the witness goes on to recall more of what the perpetrator said that would have otherwise been forgotten.

The duration of the recall period is another factor that can affect the amount of reminiscence observed. A few early researchers claimed that reminiscence was an artifact of limited initial recall periods. They stated that if the first recall period was too short, participants would logically produce "new" details at a later test, but that they would have recalled these "new" details during the first test if given more time (Erdelyi, 1996). Conversely, some researchers claimed that if the length of the recall period were too long, participants would exhaust their memory during the first test (Payne, 1987). They would be at nearly asymptotic levels of recall performance by the end of the first test, resulting in a lack of reminiscence found at later test trials. However, the problem of reaching asymptotic levels of performance should only arise if there are a finite number of TBR items to be recalled. In a real event like a crime, there may be nearly an infinite amount of details that can be recalled, so there it would be very difficult to reach the upper limits of performance, regardless of the length of the first test trial. For example, in their study involving a videotaped crime, Turtle and Yuille (1994) found reminiscence even when participants were given unlimited recall time for each test opportunity. 
Reminiscence has been found regardless of the delay between the initial encoding of the stimulus and the first recall test, but inter-test or incubation intervals can alter the amount of reminiscence gained over successive tests (Turtle \& Yuille, 1994; Dunning \& Stern, 1992). If the incubation interval is too short, anchoring effects or recency bias may present a problem, with people tending to repeat those answers given on previous tests (Madigan, 1976). However, this is not likely to present a problem given the extended intervals in real-world crime investigations. More attention should be given to incubation intervals that are too long, resulting in excess forgetting, although notably this will likely affect hypermnesia to a much greater degree than reminiscence (as seen in Turtle \& Yuille, 1994). Several studies have found greater reminiscence effects with longer intertest intervals (Smith \& Vela, 1991; Dunning \& Stern, 1992). Turtle and Yuille (1994) even found highly significant reminiscence effects testing once a week over a three-week period, with only a minor increase in errors.

There are a number of reasons for thinking that longer inter-test intervals will actually increase the amount of reminiscence gained over consecutive tests. One possibility is that people tend to restrict memory search across test trials to the most recently recalled set of items. In other words, the output elicited at an earlier test trial may interfere with the recollection of new items at a later test trial. Longer incubation intervals may weaken this recency bias in memory search. Madigan (1976) hypothesized that there is a time-dependent reduction of output interference and the results of his study support such an assertion (he found increasing amounts of reminiscence as he lengthened the incubation intervals). Along similar lines, filling an inter-test interval with a distractor 
task has been shown to bolster reminiscence. Perhaps the distractor task allows for greater release from output interference or recency bias (Smith \& Vela, 1991).

Another possible reason that longer inter-test intervals leads to larger amounts of reminiscence stems from the idea of varied retrieval. According to the stimulus sampling theory (Smith \& Vela, 1991) elements sampled from memory on two occasions will vary, with greater variability occurring over time. As the time between two testing sessions increases, so does the likelihood that a person will search his/her memory differently. In other words, as the duration of time between test trials increase, so does the likelihood that a person will change the retrieval cues he or she uses for recall. The basic tenet is that the more a person is encouraged to use different retrieval cues at two consecutive tests, the more reminiscence should be gained. For example, a distractor task may help combat the use of the same retrieval cue on two test occasions, resulting in larger amounts of reminiscence.

\section{Characteristics of an event and the selection of retrieval cues}

If varied retrieval across successive test opportunities is responsible for the phenomenon of reminiscence, then distinct retrieval cues need to be experimentally manipulated to vary between test trials. One possible way to select retrieval cues is to examine how people think about an event-i.e., observe the characteristics of their output for that event. According to the event-indexing model (Zwaan \& Radvansky, 1998), space and time are two of the most common characteristics of an event. That is, any event, such as a crime, has both a temporal and a spatial context. Temporal context refers to the chronology of the event, or how it unfolds in a story-like manner. Although most people recall stories or events starting with the beginning and moving through 
chronologically (Geiselman \& Callot, 1990), instructing a person to recollect an event in reverse order or even starting in the middle are both possible retrieval cues.

Consequently, there may be several temporal cues that could be utilized in retrieval (and, as already seen with the mnemonic of the $\mathrm{CI}$ and other studies mentioned earlier, varying temporal order can increase recall). Similarly, there may be several spatial cues that could be used in retrieval. The spatial context of an event like a crime includes the environmental layout of the scene, as well as the characters and objects (e.g., a gun) in the scene. Again, altering the spatial cues a witness uses in retrieval (e.g., instructing the witness to adopt one of the character's perspective, or to think about any important objects like a vehicle or weapon) should facilitate recall over consecutive tests (see Anderson \& Pichert, 1978).

Varying the retrieval cues used by a witness in the recall of a crime between two successive test opportunities should result in reminiscence. The amount of reminiscence gained over consecutive tests should increase when using different retrieval cues at each test opportunity because the various cues can alter the process of retrieval used by the participants in their attempts at recollection. The greatest amount of reminiscence is anticipated to occur with a between dimension change (e.g., changing from a spatial retrieval cue at an initial test to a temporal cue at a later test or vise versa) because such a change involves a very distinct alteration in retrieval cues. The next largest gain in reminiscence is expected to occur when changing within a dimension (e.g., using a forward temporal recall cue at one test and a backward temporal retrieval cue at a second test). Because reminiscence is a naturally occurring phenomenon, using the same retrieval cue at each test, or simply asking for a free recall, should still result in some 
reminiscence, although this would likely be the least amount. Finally, it is hypothesized that the number of reminiscent details will not be significantly correlated with overall accuracy rate.

Design

\section{Chapter Two: Method}

The two independent variables were the specific retrieval cue given at test time 1 (five levels) and the specific cue given at test time 2 (four levels). The design was a 5 (Test 1 cue: forward order, reverse order, undercover officer's perspective, robber's perspective, no test) X 4 (Test 2 cue: forward order, reverse order, undercover officer's perspective, and robber's perspective) between-subjects factorial design with one extra condition (free recall at time 1 followed by free recall at time 2). Both the total number of items and the number of items correctly recalled at time one and time two were noted. Participants' responses were categorized as either forgotten (given only at time 1), reminiscent (given only at time 2), contradiction (given at both test times but not in agreement with each other), or consistent (given at both test times and in agreement). These four categories of responses refer to the comparison of responses across the two tests. The dependent variables of interest included the number of reminiscent details and the accuracy rates of each category of responses (\# of correct responses / total \# responses). The number of reminiscences and the accuracy rates of these reminiscences were compared to the three other categories of responses per condition (forgotten, contradictory and consistent items). In order to examine the influence of changing cues between tests on the various types of responses, ANOVAs were calculated with the independent variable being the similarity of cues between test trials. This variable had 
four levels: repeated cue, free recall both times, within-dimension change in cue (e.g., changing from recalling event chronologically at Time 1 to recalling it in reverse order at Time 2), and between-dimension change in cues (e.g., changing from adopting officer's perspective at Time 1 to recalling event in reverse order at Time 2). In order to examine the relationship between consistency and accuracy, a correlation between the number of reminiscences and overall accuracy was calculated. One hundred ninety-six participants were randomly assigned to the various conditions.

\section{$\underline{\text { Participants }}$}

Participants were psychology students who volunteered for experiments in exchange for extra credit or credit toward a research participation requirement in their psychology class.

\section{$\underline{\text { Materials }}$}

Stimulus materials included a three-minute video of a crime (bank robbery) shown on a 19-inch television monitor. The film was made as a training video for police officers. Events in the video are as follows: A police officer enters the bank to investigate a forgery. He is spotted by one of three men who are going to rob the bank. A plain-clothed, undercover officer is already standing in line and shoots one of the potential robbers. The remaining two men grab a woman for a hostage. The plain-clothed officer shoots one of them before negotiating with the last robber. Ultimately, the assailant gives himself up and releases the hostage. An unrelated questionnaire was also used as a distractor task. It gave the scenario of a convenience store robbery and asks questions designed to examine participants' beliefs regarding the relationship between accuracy of action details and 
accuracy of appearance details. The questionnaire was four pages long and took approximately $7-10$ minutes to complete.

\section{Procedure}

Upon arriving at the experiment room, participants (in groups of 5-8 people) were given a brief introduction to the experiment (i.e., that it deals with eyewitness memory, they will watch a video, answer some questions, and then return in 48 hours). All participants were asked to sign an informed consent before beginning. All interviews were conducted in person in the experiment room, where the primary investigator or his research assistants gave instructions orally. The participants were shown the videotape of a crime and then asked to sit in a circle facing outward to minimize the social influence of participants on each other. They were given an unrelated questionnaire to serve as a filler task. Following the completion of this filler questionnaire, participants were given a blank sheet of paper. The experimenter requested that the participants pretend they were a witness to the videotaped crime and were needed by the police to provide as many details as they could remember. Depending on the experimental condition, they were asked for a free recall of the event (i.e., no additional instructions other than try to write down all they can recollect), given a specific retrieval cue prior to their recall attempt (e.g., try to think about the event in reverse chronological order; try to adopt the viewpoint of the officer in the video), or not tested at time 1. Participants were told they could write down details of the videotape in any order and manner they choose (e.g., narrative form, bulleted details, etc). One minute after they stopped writing, the experimenter asked them to try once more to recollect any additional details. Participants were allowed an 
additional two minutes to write down anything else. Following this instruction, participants were told they could leave, with the reminder to return in 48 hours.

Upon their return for the second testing, participants were given another blank sheet of paper. The same interviewer in the same setting questioned the participants. The participants were again either instructed to freely recall all the details they remembered about the event or they were given a specific retrieval cue. Once more, participants were told they could write down the details of the event in the manner they choose. Immediately following the second interview, each participant was debriefed fully and given an opportunity to ask questions about the experiment. Finally, they were thanked and dismissed with the reminder not to discuss the experiment with other students.

Either the principal investigator or one of his three trained research assistants coded and scored the participants' data. A detail master-list was created with all the possible details that could be recalled from the video-clip, with a total of 154 details (no participant recalled more than 45). Raters had to match each participant's responses to the details found on the master-list. Responses were broken down into elementary bits of information. For example, if the participant wrote down that one of the robbers wore a tan jacket and black pants, the four bits of information matched to the master-list were: tan, jacket, black, and pants. Subjective responses (e.g., "The robber was nervous") were not scored. Each bit of information was scored for accuracy by comparing it to the master-list: if the detail agreed with the master-list, it was scored as correct; if it was not on the master-list, the rater added it on and scored it as incorrect. Additionally, each bit of information was labeled as an action, description or person detail. Finally, whether the bit of information was given at time 1 or time 2 was recorded. The numbers of forgotten, 
reminiscent, contradictory and consistent details, as well as the accuracy rates for each category, were tallied for each participant.

\section{Chapter Three: Results}

The phenomenon of reminiscence was of primary interest in this study. Therefore, most of the results focus on the amount and accuracy of reminiscent details. First, I conducted an ANOVA to examine how retrieval cue similarity between Tests 1 and 2 influenced the amount of reminiscence gained over successive test trials. Parallel ANOVAs were conducted to examine the effects of cue similarity between Test 1 and Test 2 on the numbers of forgotten, contradictory and consistent details. I then compared the accuracy rates of reminiscent details to the accuracy rates of the other categories of details (forgotten, consistent, and contradictory). Finally, I examined how reminiscent details and several other predictors were related to overall accuracy rate. Alpha level was set at 0.05 for all analyses unless otherwise reported.

Inter-rater Reliability

In order to establish inter-rater reliability across conditions, four independent raters coded the number of reminiscent, forgotten, contradictory, and consistent details for twenty random participants. The average inter-rater correlations were: 0.85 for reminiscent details $($ range $=0.82-0.90), 0.92$ for forgotten details $($ range $=0.88-0.95), 0.76$ for contradictory details (range $=0.65-0.85$ ), and 0.93 for consistent details (range $=0.90$ $0.95)$.

\section{Reminiscence}

Every participant provided at least two reminiscent details and the mean number of reminiscent details per participant was 8.19. A univariate analysis of variance 
(ANOVA) was conducted on the number of reminiscent details as a function of the similarity of retrieval cues between test trials: free recall at both Tests 1 and 2, repeated cues, between-dimension change in cues and within-dimension change in cues. Changing retrieval cues between test trials significantly increased the amount of reminiscence, $\underline{F}(3,164)=23.65, \mathrm{MSe}=8.89$. The frequency means and standard deviations of reminiscent responses are summarized in Table 1 (page 36). The results of a Tukey's-b post hoc test showed that the mean numbers of reminiscent details for between-dimension changes in cues and within-dimension changes were significantly higher than the mean numbers of reminiscent details for free recall conditions and conditions with repeated cue instructions (e.g., use of reverse order cue at Tests 1 and 2). There were no significant differences, however, between those conditions using within-dimension changes and those using between-dimension changes. Since there was no main effect of type of cue change for between and within-dimension changes, these two conditions were collapsed in all later analyses.

\section{Forgotten, Consistent and Contradictory Details}

The number of forgotten details was also significantly affected by the change in retrieval cues from Test 1 to Test 2. A univariate ANOVA was conducted on the number of forgotten details as a function of the similarity of cues between test trials. The results of this ANOVA showed that changing retrieval cues between Tests 1 and 2 significantly affected the number of forgotten details recalled, $\underline{F}(3,164)=7.78, \mathrm{MSe}=8.50$. The results of a Tukey's-b post hoc test revealed that the mean numbers of forgotten details for within-dimension and between-dimension changes in retrieval cues $(\underline{\mathrm{Ms}}=8.65$ and 7.92 respectively) were not significantly different from one another, but they were both 
significantly lower than the mean numbers for free recall or repeated cue conditions $(\underline{M s}=10.50$ and 10.29 respectively). Also, the mean numbers of forgotten details for free recall and repeated cue conditions did not differ from each other. The frequency means and standard deviations of forgotten responses are summarized in Table 1 (page 36).

Two univariate ANOVAs were also conducted on the number of consistent details and the number of contradictory details as a function of cue similarity between Tests 1 and 2. Both the number of consistent details and the number of contradictory details were not affected by the similarity of cues between test trials, $\underline{F}(3,164)=1.17$, n.s., $M S e=23.05$ and $\underline{F}(3,164)=1.23$, n.s., $M S e=0.25$ respectively. The frequency means and standard deviations of consistent and contradictory responses are summarized in Table1 (page 36). Accuracy Rates at Test 1 and Test 2

Accuracy rate reflects the percentage of responses that are correct (number of correct responses / total number of responses). Two separate univariate ANOVAs were conducted on the accuracy rate of responses at Test 1 and the accuracy rate of responses at Test 2 as a function of cue similarity. The results of these ANOVAs showed that both the accuracy rate at Test 1 and the accuracy rate at Test 2 were not significantly affected by cue similarity, $\underline{F}(3,164)=1.00$, n.s., $M S e=0.01$ and $\underline{F}(3,164)=1.62$, n.s., $M S e=0.01$ respectively. Four univariate ANOVAs were also calculated to examine if the accuracy rates of the four types of details differed significantly as a function of the similarity of cues between test trials. None of these were significant. Accuracy Rates for Forgotten, Reminiscent, Contradictory and Consistent Details

The results of a repeated measures ANOVA indicated that the accuracy rates for the three different types of details given at Test 1 (forgotten, contradictory, and 
consistent) were significantly different from each other, $\underline{F}(2,66)=14.89, \mathrm{MSe}=0.07$. The results of a Tukey's b post-hoc test revealed that the mean accuracy rate for consistent details $(\underline{M}=.95)$ was significantly higher than for forgotten details $(\underline{M}=.93)$, which was significantly higher than for contradictory details $(\underline{M}=.62)$. The results of a repeated measures ANOVA showed that the mean accuracy rates for the three types of details given at Test 2 (reminiscent, contradictory, and consistent) were significantly different from each other, $\underline{F}(2,66)=49.10, M S e=0.07$. The results of a Tukey's $b$ post-hoc test indicated that the mean accuracy rate for consistent details $(\underline{M}=.95)$ was significantly higher than for reminiscent details $(\underline{M}=.87)$, which was significantly higher than for contradictory details $(\underline{\mathrm{M}}=.35)$.

Planned paired samples t-tests were computed comparing the accuracy rates of forgotten and reminiscent details, as well as comparing the accuracy rates of contradictions given at Tests 1 and 2 . The paired samples t-tests revealed that the accuracy rate for reminiscent details $(\underline{\mathrm{M}}=.87)$ was significantly lower than that of forgotten details $(\underline{\mathrm{M}}=.93), \underline{\mathrm{t}}(167)=-7.03, \mathrm{MSe}=0.01$. The accuracy rates of contradictory details given at Times $1(\underline{M}=.62)$ and $2(\underline{M}=.35)$ were not significantly different from one another, $\mathrm{t}(33)=1.72, \mathrm{MSe}=0.15$. [This non-significant finding is probably due to high variability in the number of contradictory details, since there were very few observations per participant.] To summarize, consistent details were significantly more accurate than forgotten details, which in turn were significantly more accurate than reminiscent details, which were significantly more accurate than contradictory details. The mean accuracy rates for the various kinds of details are given in Table 2 (page 37). 


\section{Relation Between Reminiscent Details and Overall Accuracy}

The Pearson correlation between the number of reminiscent details and overall accuracy rate was nonsignificant, $\mathrm{r}=-0.15, \mathrm{~N}=168$. Further correlational analyses showed that the proportion of reminiscent details (the number of reminiscent details/total number of details) was not significantly correlated with either the accuracy rate of details given at Time $1(r=0.03)$ or the accuracy rate of details at Time $2(r=-0.14)$. Moreover, both the correlation between the number of reminiscent details and accuracy rate at Time 1 ( $r=$ -0.12 ) and the correlation between the number of reminiscent details and accuracy rate at Time $2(r=-0.11)$ were non-significant.

\section{Correlations of Forgotten, Contradictory, and Consistent Details and Overall Accuracy}

In order to examine the role of other predictors on overall accuracy, several additional analyses were performed. The correlations between the numbers of consistent, contradictory, and forgotten details and overall accuracy rate were examined. Both the numbers of forgotten details and consistent details were not significantly correlated with overall accuracy, $r=0.01, N=168$, and $r=-0.15, N=168$, respectively. The number of contradictory details, however, was significantly negatively correlated with overall accuracy rate, $r=-0.17, N=168$. For an additional test dealing with contradictions, the participants were categorized as either giving no contradictory details or as giving at least one contradictory detail. A t-test revealed no significant differences in overall accuracy rate for these two groups, $\underline{\mathrm{t}}(166)=1.19, \mathrm{MSe}=0.01$.

The only other predictor of overall accuracy, besides number of contradictory details, was the length of testimony. Overall accuracy rate was significantly negatively correlated with total number of statements per participant, $\mathrm{r}=-0.20, \mathrm{~N}=168$. That is, the 
greater the number of details recalled, the less accurate was the overall testimony.

Because the total number of statements was negatively correlated with overall accuracy, I conducted another correlational analysis on the four categories of details and overall accuracy rate after partialling out total number of statements. None of the four categories of details significantly correlated with overall accuracy after controlling for total number of statements. All correlations were between -0.03 and 0.15 , thus accounting for very little variance in overall accuracy rate.

\section{Chapter Four: Discussion}

Inconsistencies in the form of reminiscence will likely be challenged in court. In fact, both older and more recently published legal texts encourage opposing attorneys to try to elicit such inconsistencies as a means of discrediting witnesses (Bailey \& Rothblatt, 1971; Dombroff, 1985; Mueller \& Kirkpatrick, 1996). For instance, as Mueller and Kirkpatrick (1996) state, "prior inconsistent statements have long been admissible for impeachment, meaning the adverse party could use them for the limited purpose of trying to destroy credibility" (p. 145). Yet the data from the current study suggest that the assumptions of legal decision makers regarding inconsistent testimony may be wrong. Every participant provided some reminiscent details. This suggests that reminiscence is a natural product of repeated interviewing. Moreover, the number of reminiscent items recalled varied systematically with a change in retrieval cues, as predicted by standard principles of retrieval. Additionally, reminiscence does not necessarily indicate inaccurate testimony. The accuracy rate of these reminiscent items was relatively high $(\underline{M}=.87)$ and not that much lower than the accuracy rate of consistent items $(\underline{M}=.95)$. Thus, reminiscence is not some strange phenomenon that should be challenged in court. 
The findings in the present investigation mirror those of Turtle and Yuille (1994), who also found reminiscence to be a ubiquitous and generally accurate phenomenon. They found evidence of accurate reminiscent items regardless of the delay between test trials, number of recall attempts, or the opportunity to review previous statements. The results of their study, in conjunction with the current investigation, should point to the conclusion that reminiscence is not a viable reason to impeach a witness.

\section{Varying Retrieval Cues and Reminiscence}

The causes of reminiscence have never been firmly established, even though it is a pervasive phenomenon. I initially proposed that varying retrieval cues between test opportunities would increase the amount of reminiscence. The results of the study strongly supported this hypothesis. There were significantly more reminiscent details recalled in conditions where retrieval cues changed between Tests 1 and 2 than in the repeated cue or free recall conditions. This difference demonstrates that offering people novel ways to search their memories can have the beneficial effect of increasing what they recall. As Tulving (1974) described, recollection (the output) can be viewed as a product of both the stored input and the retrieval cue(s). Changing the retrieval cue used in a recollection attempt alters the process of retrieval, and consequently, what information is remembered. Since there may be several retrieval paths to a stored event, information not obtained with one retrieval cue may be accessed through a different cue. Each retrieval cue has some probability of accessing stored details of an event. Hence, changing cues from Test 1 to Test 2 may result in the recollection of previously unrecalled details (i.e., reminiscence). At least one cause of reminiscence therefore is the (dis)similarity of the retrieval cues (or, more broadly, environments) at the two tests. 
A possible explanation for these results is that each retrieval cue activates different dimensions or properties of an event. In other words, different dimensions of the event are made differentially salient through the use of a variety of retrieval cues. The study by Anderson and Pichert (1978) highlight the point that changing retrieval cues (in their study, perspective) alters the salient dimension a witness focuses on when recalling an event. They found that having participants switch perspectives in successive recall attempts caused participants to produce more information pertinent to the activated perspective that had been unimportant to the previous perspective. For example, switching from remembering the story from a burglar's perspective to remembering from a homebuyer's perspective led to the recall of new, previously unrecalled information relevant to the homebuyer (e.g., number of bathrooms; Anderson \& Pichert, 1978). In other words, altering which perspective was salient to the participant (via new retrieval cues) systematically influenced what was recalled. In the context of the present experiment, using a retrieval cue that directs attention to a perpetrator should result in the witness recalling details concerning people. Using a different retrieval cue, for example directing attention to objects in the scene, alters what dimension or property of the event is salient to the witness. Consequently, previously unrecalled information specific to this "new" salient dimension is more likely to be recollected (e.g., objects such as a car or weapon).

I initially expected that shifting between dimensions (e.g., from a temporal to a spatial cue) involved a greater alteration in retrieval paths than a within-dimension change (e.g., from one temporal cue to another temporal cue). I therefore anticipated that more reminiscent details would be recalled in conditions using between-dimension 
changes than within-dimension changes. However, there was no difference in the number of reminiscent details recalled in conditions involving between-dimension changes and within-dimension changes of retrieval cues. It is unclear why no differences were found between these two groups. Perhaps it is not a matter of the degree of change in cues in order to produce reminiscence, but only that there is an alteration of retrieval cues, allowing the witness access to several different retrieval paths to a stored event.

\section{Changing Cues Increases Reminiscence and Decreases Forgetting}

Instructing people to change retrieval cues over successive recall attempts increases the likelihood that people will think about the event in a novel way. Since they are not thinking about the event in the same manner, one might expect that a change in cues between Tests 1 and 2 would reduce the likelihood of recalling the same details at both times. Therefore, changing cues between Tests 1 and 2 should cause an increase in reminiscent details as well as an increase in forgotten details. In fact, however, changing cues between Test 1 and Test 2 increased the number of reminiscent details recalled yet it decreased the number of forgotten details. It is not readily apparent to me why changing cues between Test 1 and 2 decreased the number of forgotten details in the participants' narrative. At the very least, this suggests that different cognitive processes underlie reminiscence and forgetting. Since the focus of the current investigation was on varying retrieval cues and reminiscence, it would be worthwhile for future researchers to examine why different patterns of data emerged for reminiscent and forgotten items.

Practically, the results of the current investigation suggest that police interviews of cooperative witnesses can elicit more information by asking questions that utilize various retrieval cues for memory of a crime. An increase in reminiscent details, 
combined with decreases in forgotten details, demonstrates the effectiveness of using a variety of retrieval cues when conducting multiple interviews. For example, the police could ask a witness to adopt the perspective of the criminal, or focus on different objects at the scene, or think about the event starting at the end and moving backwards. Using a variety of cues in recall attempts has already proven effective in the Cognitive Interview (CI), where mnemonics such as recalling an event in a multitude of orders and changing perspectives during recall increase the number of accurate details a witness recollects in an interview (Fisher \& Geiselman, 1992; Boon \& Noon, 1994; Chandler \& Fisher, 1996). Accuracy of Individual Statements

The current investigation did find that reminiscent details were less accurate than consistent and forgotten details. Nonetheless, the vast majority (87\%) of the reminiscent items were accurate. Therefore, it would be foolhardy to dismiss all previously unrecalled information as inaccurate. Instead, the majority of these details are factually correct. Additionally, some of this information may lead to new physical evidence or testimony so more of the facts of the case are available in court. The new pieces of information may be exceptionally valuable or even the key to closing certain cases. Obviously there is no way of telling which "new" details are accurate in an actual investigation, but with such a high accuracy rate, it seems wise for police to pursue any leads that may arise from reminiscent details.

The absolute difference between the accuracy rates of reminiscent items and forgotten items was quite small, though significant $(\underline{M}=.87$ vs. $\underline{M}=.93$ respectively). It is interesting to note though that forgotten details were also significantly less accurate than consistent details. Yet forgotten details are hardly challenged in court or during police 
interviews. Even though forgotten items are just as inconsistent as reminiscent items, people may not view them as such. Apparently, people are comfortable with the notion of forgetting earlier-recalled details but not remembering previously-forgotten or unrecalled details. People intuitively accept that forgetting is natural part of memory but find it difficult to accept reminiscence, presumably because most people encounter forgetting to a greater extent than reminiscence. People may also be accustomed to thinking in terms of the classical forgetting curve (i.e., the natural phenomenon that memory decreases with the passage of time). The small difference between accuracy rates for these two types of items, however, hardly accounts for this difference in practice.

Contradictions, not surprisingly, were the least accurate category of detail. Most legal texts, though, simply suggest attacking all inconsistencies as grounds to destroy witness credibility (see, for instance, earlier quote at beginning of Discussion; Mueller \& Kirkpatrick, 1996). Perhaps legal decision makers should make a distinction regarding the type of inconsistency in a witness's account (reminiscence vs. contradiction). It should be easy for lawyers to identify contradictions in testimony if they have access to previous interviews. Although not that common, direct contradictions (where the witness gives two distinct accounts at different times) will obviously be incorrect at least once, if not both times. It therefore makes sense that legal decision makers question the accuracy of contradictory details to a greater extent than reminiscent details, instead of denoting all inconsistencies indicative of inaccuracy. It seems that not all inconsistencies are equally invalid in that reminiscent (and forgotten) inconsistencies are not nearly as indicative of inaccuracy as are contradictions. 


\section{Accuracy of Witness}

Reminiscence and overall accuracy. Reminiscent details were less accurate than forgotten and consistent details. Yet the number of reminiscent details within a witness's testimony was not correlated with overall accuracy of testimony. How can this discrepancy exist? The results of several recent studies in the eyewitness literature have demonstrated that accuracy for recalling one aspect or dimension of information is not correlated with accuracy of recalling another dimension (Brewer et al., 1999; Fisher, Schreiber, Burguera, \& Alvarez, 2003; Mitchell, Haw, \& Fisher, 2003). Therefore, a witness who may not be able to accurately describe one dimension (e.g., the getaway car) may still offer valuable, correct information regarding a different dimension (e.g., the criminal). That is, the event is not stored holistically in memory. Different aspects of the event are stored independently, so that retrieving information about one dimension does not facilitate retrieving information about another dimension. Inconsistencies that occur in a witness' account will be limited to that particular dimension. Therefore, even if recall accuracy for one dimension is poor (e.g., the witness did not encode colors very well), overall accuracy of testimony can still be high. These recent findings of independently processed objects within a scene are compatible with feature-integration theory (Triesman \& Gelade, 1980). Briefly, this theory postulates that functionally separable dimensions/components of an event are composed of simple features and are processed independently of one another.

Predictors of overall accuracy. The numbers of reminiscent, consistent, and forgotten details did not predict overall accuracy rate in the present study. However, the number of contradictions was significantly correlated with overall accuracy rate such that 
overall accuracy rate decreased as the number of contradictions increased. Nonetheless, this correlation, although significant, was very small $(r=-0.16)$ and thus only accounted for approximately $2.5 \%$ of the variance in overall accuracy rate. Therefore, the number of inconsistencies (forgotten, reminiscent and contradictory items) is not a good predictor of overall accuracy. Additionally, a more careful analysis of the data revealed that the previously significant correlation between the number of contradictions and accuracy rate became non-significant after the total number of statements was partialled out. The present investigation found that the greater the total number of statements recalled, the greater the likelihood that inaccuracies will be present in the account. However, the correlation between the numbers of inconsistent details and overall accuracy and the correlation between the number of statements and overall accuracy were roughly comparable in magnitude. Therefore, no predictor of overall accuracy of testimony was found that accounted for a sizable proportion of variance in overall accuracy of testimony.

\section{Potential Limitations}

There are several potential limitations to this study. First, the event used was a videotape of a simulated bank robbery. Obviously, real eyewitnesses view an actual live crime, where other factors (besides it being real) such as arousal, weapon-focus, or position of the witness may play a larger role than in a videotaped, simulated crime. It is certainly possible that such factors would affect encoding such that the retrieval cues used in the current study may not be effective in a real crime. For instance, a witness to an actual crime may focus most of his or her attention on the criminal's gun and therefore not be able to adopt the perspective of other people at the crime scene. Another 
possibility is that witnesses who are highly aroused may be less mentally flexible, particularly immediately following the crime. In other words, they may have difficulty utilizing different retrieval cues such as varying perspectives during recall, due to the emotionally charged, arousing event they just witnessed.

Another potential limitation for the current study is that participants were asked to write down their answers, which allows for the opportunity to review what was previously recalled. This opportunity to review should result in the reviewed material being more likely to be recalled again at later interviews (i.e., a decrease in forgetting). In an actual investigation, the interviewer typically records responses from an eyewitness, who simply gives oral answers to specific questions, which does not allow for any review of previously recalled material. Another potential caveat for the present investigation concerns the different processes that may underlie reminiscence to open-ended questions and reminiscence to closed-ended questions. For open-ended questions, little direction is given about how to remember the event. Thus there is more potential variation in the functional retrieval cue with open-ended questions than with specific probes. Reminiscence to closed-ended questions, where a witness responds with a "don't know" at Time 1 but then gives an answer at Time 2, may reflect something qualitatively different than reminiscence for open-ended questions. For closed-ended questions, reminiscence may not result from any variation in the functional retrieval cues but for another reason. For instance, the witness may be using a lower output threshold in responding, such that he or she may simply be giving more details at Time 2 . In this case, it is likely that the reminiscent items will be less accurate than those recalled with openended questions. Another possibility is that the witness is conjuring details at Time 2 to 
appease the interviewer because the witness believes the previous response of "don't know" was inadequate (hence, why the same closed-ended question was being asked again at Time 2).

Given the variety of concerns, the data from this study may not generalize to an actual investigation. First, the time between interviews in this study was only two daysa real investigation may have weeks between interviews. Loss of information in this situation will likely be more severe than the loss associated with a two-day test interval, and the use of novel retrieval cues may be less effective with the more severely decayed memory traces. However, several studies have shown evidence of reminiscence with longer test intervals. Turtle and Yuille (1994), testing once a week over a three-week period, still found reminiscence at each of the three successive recall attempts. Even more impressive, Poole and White (1993) found evidence of reminiscence, among both children and adults, after a two-year delay in questioning. A second difference from a real investigation is that the setting was the same at both interviews in the present study. The setting would likely change in an actual investigation, where it is also likely that more than only two interviews would take place. In the situation where a multitude of interviews occur, the more times a detail is recalled in prior attempts, the more likely that it would be recalled again later (i.e., decreases the likelihood those details will be forgotten; Poole \& White, 1995). The present investigation did not focus on the absolute amount of consistency across tests. Third, consider that the same interviewer was used at both tests in the present study. An actual investigation would likely involve several different people questioning the witness. Given the variety of motives, strategies, question formats, etc... that people use in interviewing a witness, it should not be 
surprising that two people interviewing the same witness could elicit different testimonies from that witness.

Most of the differences, however, between the current study and an actual investigation (i.e., short inter-test intervals, opportunities to review, the same setting and interviewer in this study) would, if anything, serve to reduce reminiscence and increase consistent details in the present study. Moreover, these differences between a real investigation and the present investigation should not detract from the implications and conclusions found here: (a) reminiscence is a ubiquitous phenomenon, (b) reminiscence responds systematically to theoretically-driven manipulations (i.e., retrieval cues) such that changing cues between Tests 1 and 2 serves to increase the amount of these "new" details, (c) reminiscent items are typically accurate ( $87 \%$ were factually correct), and (d) the number of reminiscent items was not correlated with overall accuracy of testimony.

\section{Caveat for Multiple Testing}

The phenomenon of reminiscence is a positive consequence of repeated testing. However, one potential negative consequence of conducting multiple tests is the slight but reliable increase in the number of errors that may accompany repetitive testing as compared to a single test (Bornstein et al., 1998). Scrivner and Safer (1988) for instance, testing participants in four successive recall trials over a two-day period, found a significant increase across trials in the number of minor errors (e.g., mistaking the color of burglar's hair). However, a few things should be kept in mind when considering the increase in the number of errors that may occur with successive test trials. Most notably, some researchers actually found an increase in accuracy accompanying repeated testing of open-ended questions (Dent \& Stephenson, 1979), while others did not find increases 
in error rates (Poole \& White, 1993; Turtle \& Yuille, 1994 Exp.1). Moreover, these errors always pale in comparison with the number of additional correct details recalled, as reflected in the current study as well as past research (Scrivner \& Safer, 1988; Bornstein et al., 1998). Also, as previously stated, some of the new information may lead to new physical evidence or testimony so more of the facts of the case are available in court. The new pieces of information may be exceptionally valuable or even the key to closing certain cases. This new information should not be dismissed as inaccurate or useless for fear that some of the information may be erroneous.

\section{Conclusion}

Reminiscence has previously been shown to occur naturally regardless of the stimulus materials, the recall procedures used, the inter-test interval or the test trial durations (Payne, 1987; Scrivner \& Safer, 1988; Dunning \& Stern, 1992; Poole \& White, 1993; Turtle \& Yuille, 1994). In the present investigation, reminiscent inconsistencies were found to vary systematically with a change in retrieval cues over test trials. Regardless of the retrieval cue used in recall, reminiscent inconsistencies will arise over repetitive testing. Such inconsistencies are common and natural. In addition, these inconsistencies are frequently correct and thus do not imply inaccurate testimony. Attorneys should therefore not reflexively use reminiscent inconsistencies to destroy a witness's credibility. At the very least, the mere existence of reminiscent inconsistencies should not be used as a means to impeach a witness, as many legal texts recommend. 
Table 1

Mean frequencies (and standard deviations) of types of details as function of cue similarity between Tests 1 and

\begin{tabular}{lcccc} 
& \multicolumn{4}{c}{ Response Category } \\
\cline { 2 - 5 } Cue similarity & $\begin{array}{c}\text { Reminiscent } \\
\text { items }\end{array}$ & $\begin{array}{c}\text { Forgotten } \\
\text { items }\end{array}$ & $\begin{array}{c}\text { Consistent } \\
\text { items }\end{array}$ & $\begin{array}{c}\text { Contradictory } \\
\text { items }\end{array}$ \\
\hline Repeated cues & $6.1_{\mathrm{a}}(3.2)$ & $10.5_{\mathrm{a}}(3.8)$ & $19.5_{\mathrm{a}}(4.3)$ & $0.2_{\mathrm{a}}(0.5)$ \\
Between-dimension change & $10.0_{\mathrm{b}}(2.8)$ & $8.0_{\mathrm{b}}(2.5)$ & $21.2_{\mathrm{a}}(5.5)$ & $0.3_{\mathrm{a}}(0.5)$ \\
Within-dimension change & $10.2_{\mathrm{b}}(3.2)$ & $8.7_{\mathrm{b}}(2.8)$ & $20.2_{\mathrm{a}}(4.9)$ & $0.2_{\mathrm{a}}(0.6)$ \\
Free recall & $6.5_{\mathrm{a}}(2.5)$ & $10.3_{\mathrm{a}}(3.4)$ & $21.2_{\mathrm{a}}(3.8)$ & $0.1_{\mathrm{a}}(0.3)$ \\
\hline Note. Frequency means per column that do not share subscripts differ at the $\mathrm{p}<.05$ level.
\end{tabular}

Table 2

Mean accuracy rates (and standard deviations) for forgotten, reminiscent, contradictory and consistent details

\begin{tabular}{lcc}
\hline Response type & Proportion accurate at Time 1 & Proportion accurate at Time 2 \\
\hline Consistent & $0.95_{\mathrm{a}}(0.04)$ & $0.95_{\mathrm{a}}(0.04)$ \\
Forgotten & $0.93_{\mathrm{b}}(0.06)$ & - \\
Reminiscent & - & $0.87_{\mathrm{c}}(0.05)$ \\
Contradictory & $0.62_{\mathrm{d}}(0.08)$ & $0.35_{\mathrm{d}}(0.10)$ \\
\hline
\end{tabular}

Note. Means that do not share subscripts differ at the $\mathrm{p}<.05$ level. 


\section{References}

Anderson, M.C., Bjork, R.A. and Bjork, E.L. (1994). Remembering can cause forgetting: Retrieval dynamics in long-term memory. Journal of Experimental Psychology: Learning, Memory and Cognition, 20, 1063-1087.

Anderson, M.C., Bjork, R.A. and Bjork, E.L. (2000). Retrieval induced forgetting: Evidence for a recall-specific mechanism. Psychological Bulletin \& Review, 7, 522-530.

Anderson, M.C. and Spellman, B.A. (1995). On the status of inhibitory mechanisms in cognition: Memory retrieval as a model case. Psychological Review, 102, 68-100.

Anderson, R.C. and Pichert, J.W. (1978). Recall of previously unrecallable information following a shift in perspective. Journal of Verbal Learning and Verbal Behavior, 17, 1-12.

Boon, J. and Noon, E. (1994). Changing perspectives in cognitive interviewing. Psychology, Crime and Law, 1, 59-69.

Bornstein, B.H., Liebel, L.M. and Scarberry, N.C. (1998). Repeated testing in eyewitness memory: A means to improve recall of a negative emotional event. Applied Cognitive Psychology, 12, 119-131.

Brewer, N., Potter, R., Fisher, R.P., Bond, N. and Luszcz, M.A. (1999). Beliefs and data on the relationship between inconsistency and inaccuracy of eyewitness testimony. Applied Cognitive Psychology, 13, 297-313.

Brock, P., Fisher, R.P. and Cutler, B.L. (1999). Examining the Cognitive Interview in a double-test paradigm. Psychology, Crime \& Law, 5, 29-45.

Buschke, H. (1974). Spontaneous remembering after recall failure. Science, 184, 579581 .

Chandler, C.C. and Fisher, R.P. (1996). Retrieval processes and witness memory. In R.A. Bjork \& E.L. Bjork (Eds.), Memory (pp. 493-524). New York: Academic Press.

Dent, H.R. and Stephenson, G.M. (1979). An experimental study of the effectiveness of different techniques of questioning child witnesses. British Journal of Social and Clinical Psychology, 18, 41-51.

Dombroff, M.A. (1985). Direct and cross-examination. New York: John Wiley \& Sons. 
Dunning, D. and Stern, L.B. (1992). Examining the generality of eyewitness hypermnesia: A close look at the time delay and question type. Applied Cognitive Psychology, 6, 643-657.

Erdelyi, M.H. (1996). Recovery of unconscious memories: hypermnesia and reminiscence. Chicago, IL: The University of Chicago Press.

Erdelyi, M.H. and Becker, J. (1974). Hypermnesia for pictures: Incremental memory for pictures but not for words in multiple recall trials. Cognitive Psychology, 6, 159171.

Eugenio, P., Buckhout, R., Kostes, S. and Ellison, K. (1982). Hypermnesia in the eyewitness to a crime. Bulletin of the Psychonomic Society, 19, 83-86.

Fisher, R.P. (1995). Interviewing victims and witnesses of crime. Psychology, Public Policy, and Law, 1, 732-764.

Fisher, R.P. and Cutler, B.L. (1995). The relation between consistency and accuracy of eyewitness testimony. In G. Davis, S. Lloyd-Bostock, M. McMurran and C. Wilson (Eds), Law and criminal justice: International developments in research and practice. Berlin: De Gruyter.

Fisher, R.P. and Geiselman, R.E. (1992). Memory enhancing techniques for investigative interviewing: The Cognitive Interview. Springfield, IL: Charles C. Thomas.

Fisher, R.P., Geiselman, R.E. and Amador, M. (1989). Field test of the Cognitive Interview: Enhancing the recollection of actual victims and witnesses of crime. Journal of Applied Psychology, 74, 722-727.

Fisher, R.P, Mello, E.W. and McCauley, M.R. (1999). Are jurors' perceptions of eyewitness credibility affected by the Cognitive Interview? Psychology, Crime \& Law, 5, 167-176.

Fisher, R.P., Schreiber, N., Burguera, M., and Alvarez, C. (2003). Consistency of eyewitness recollection as an indicator of accuracy. Poster presented at $44^{\text {th }}$ annual meeting of the Psychonomic Society: Vancouver, Canada.

Geiselman, R.E. and Callot, R. (1990). Reverse versus forward recall of script-based texts. Applied Cognitive Psychology, 4, 141-144.

Geiselman, R.E., Fisher, R.P., MacKinnon, D.P., and Holland, H.L. (1986). Enhancement of eyewitness memory with the cognitive interview. American. Journal of Psychology, 99, 385-401. 
Iannuzzi, J.N. (1999). Handbook of cross-examination: The mosaic art $\left(2^{\text {nd }}\right.$ ed.). New Jersey: Prentice Hall.

Madigan, S. (1976). Reminiscence and item recovery in free recall. Memory \& Cognition, 4, 233-236.

Meuller, C. and Kirkpatrick, L. (1996). Evidence under the rules: Text, cases, and problems $\left(3^{\text {rd }}\right.$ Ed. $)$. New York: Little, Brown, \& Company.

Mitchell, T., Haw, R., and Fisher, R.P. (2003). Eyewitness accuracy: Can accuracy for one statement be predictive of more "global" accuracy? Paper presented at European Psych-Law Society. Edinburgh, Scotland.

Payne, D.G. (1987). Hypermnesia and reminiscence in recall: A historical and empirical review. Psychological Bulletin, 101, 5-27.

Poole, D.A. and White, L.T. (1993). Two years later: Effects of question repetition and retention interval on the eyewitness testimony of children and adults.

Developmental Psychology, 29, 844-853.

Poole, D.A. and White, L.T. (1995). Tell me again and again: Stability and change in the repeated testimonies of children and adults. In M. Zaragosa, J. Graham, G. Hall, R. Hirschman, and Y. Ben-Porath (Eds), Memory and testimony in the child witness. Thousand Oaks, CA: Sage Publishers.

Roediger III, H.L., Payne, D.G. and Gillespie, G.L. (1982). Hypermnesia as determined by level of recall. Journal of Verbal Learning and Behavior, 21, 635-655.

Scrivner, E. and Safer, M.A. (1988). Eyewitnesses show hypermnesia for details about a violent event. Journal of Applied Psychology, 73, 371-377.

Smith, S.M. and Vela, E. (1991). Incubated reminiscence effects. Memory \& Cognition, $19,168-176$.

Treisman, A.M. and Gelade, G. (1980). A feature integration theory of attention. Cognitive Psychology, 12, 97-136.

Tulving, E. (1974). Cue-dependent forgetting. American Scientist, 62, 74-82.

Tulving, E. and Thomson, D.M. (1973). Encoding specificity and retrieval processes in episodic memory. Psychological Review, 80, 352-373. Tulving, E. and Watkins, M.J. (1975). Structure of memory traces. Psychological Review,
82, 261-275. 
Turtle, J.W. and Yuille, J.C. (1994). Lost but not forgotten details: Repeated eyewitness recall leads to reminiscence but not hypermnesia. Journal of Applied Psychology, 79, 260-271.

Wheeler, M.A. (1995). Improvement in recall over time without repeated testing: Spontaneous recovery revisited. Journal of Experimental Psychology: Learning, Memory and Cognition, 21, 173-184.

Whitten, W.B. and Leonard, J.M. (1981). Directed search through autobiographical memory. Memory \& Cognition, 9, 566-579.

Wyer, Jr., R.S. \& Radvansky, G.A. (1999). The comprehension and validation of social information. Psychological Review, 106, 89-118.

Zwaan, R.A. and Radvansky (1998). Situation models in language comprehension and memory. Psychological Bulletin, 123, 162-185. 